\title{
Glycyrrhizin Treatment Facilitates Extinction of Conditioned Fear Responses After a Single Prolonged Stress Exposure in Rats
}

\author{
Shuhua Laia Gangwei Wu ${ }^{\mathrm{b}}$ Zhixian Jiang ${ }^{\mathrm{c}}$ \\ aEmergency Pharmacy, Quanzhou 1st Hospital Affiliated to Fujian Medical University, Quanzhou \\ 1st Hospital, Fujian, 'Department of Pharmacy, Fujian Provincial Hospital, Fuzhou, Fujian, Inpatient \\ Department, Quanzhou 1st Hospital Affiliated to Fujian Medical University, Chendong Branch of \\ Quanzhou 1st Hospital, Quanzhou, Fujian, China
}

\section{Key Words}

High mobility group box chromosomal protein 1 - Toll-like receptor 4 - Basolateral amygdala - Post-traumatic stress disorder • Conditioned fear response $\cdot$ Extinction

\begin{abstract}
Abtract
Background/Aims: Impaired fear memory extinction is widely considered a key mechanism of post-traumatic stress disorder (PTSD). Recent studies have suggested that neuroinflammation after a single prolonged stress (SPS) exposure may play a critical role in the impaired fear memory extinction. Studies have shown that high mobility group box chromosomal protein 1 (HMGB-1) is critically involved in neuroinflammation. However, the role of HMGB-1 underlying the development of impairment of fear memory extinction is still not known. Methods: Thus, we examined the levels of HMGB-1 in the basolateral amygdala (BLA) following SPS using Western blot and evaluated the levels of microglia and astrocytes activation in the BLA after SPS using immunohistochemical staining. We then examined the effects of pre-SPS intra-BLA administration of glycyrrhizin, an HMGB1 inhibitor, or LPS-RS, a competitive TLR4 antagonist, on subsequent post-SPS fear extinction. Results: We found that SPS treatment prolonged the extinction of contextual fear memory after the SPS. The impairment of SPS-induced extinction of contextual fear memory was associated with increased HMGB1 and Toll-like receptor 4 (TLR4) levels in the BLA. Additionally, the impairment of SPS-induced extinction of contextual fear memory was associated with increased activation of microglia and astrocyte in the BLA. Intra-BLA administrations of glycyrrhizin (HMGB-1 inhibitor) or LPS-RS (TLR4 antagonist) can prevent the development of SPS-induced fear extinction impairment. Conclusion: Taken together, these results suggested that SPS treatment may not only produce short term effects on the HMGB1/TLR4-mediated pro-inflammation, but alter the response of microglia and astrocytes to the exposure to fear associated contextual stimuli.




\section{Introduction}

Post-traumatic stress disorder (PTSD) is characterized as long-lasting symptoms of mental disorders including emotional irritability and avoidance behavior due to the experience of life-threatening events or severe trauma [1-5]. PTSD patients usually experience severe anxiety, fear, and trauma related environmental escape, which seriously decrease the life quality of patients $[1,2]$. Thus, one of the focuses on PTSD studies is to investigate the neuropathophysiological mechanisms underlying the development of PTSD [6] in order to develop effective intervention to prevent PTSD.

Impaired fear memory extinction is widely considered as a key mechanism of PTSD. Thus, successful prevention of PTSD needs to prevent the impairment of fear memory extinction. Fear extinction refers to the decrease in conditioned fear responses that occur with repeated presentation of the unreinforced conditioned fear stimulus [7]. Studies have shown that extinction represents new learning and that its expression can be easily disrupted. For instance, a single prolonged stress exposure is capable of impairing subsequent fear memory extinction $[8,9]$. Intriguingly, several clinical studies have shown that levels of the innate immune cytokines, such as interleukin (IL)-1, IL-6, and tumor necrosis factor (TNF)- $\alpha$, are correlated with impaired fear extinction [10-12], suggesting that neuroinflammation after a single prolonged stress exposure may play a critical role in the impaired fear memory extinction.

Recent studies have demonstrated that exposure to a stressor not only produces a transient neuroinflammatory response, but also alters responses to a subsequent inflammatory challenge. Several studies have found that prior exposure to an acute or chronic stressor potentiates the neuroinflammatory and microglial pro-inflammatory response. These stressors include chronic social defeat, chronic unpredictable mild stress and acute inescapable tail shock [13-17]. Furthermore, it has been implicated that extracellular high mobility group box chromosomal protein 1 (HMGB1) is an important molecule in stressinduced priming of microglia [18]. For example, inescapable tail shocks increase HMGB1 protein in the hippocampus [19]. However, whether an increased amount of HMGB-1 underlies the development of impairment of fear memory extinction is still not known.

The amygdala is a critical structure for fear memory extinction [20-22]. Specifically, the basolateral amygdala (BLA) plays a critical role in driving the conditioned stimuli to elicit freezing and other related conditional fear responses [23]. Recent behavioral and pharmacological studies have reported participation of the BLA in fear extinction learning. However, whetherstress-inducedneuroinflammation primingintheBLAunderlies subsequent impairment of fear extinction has not been investigated. Therefore, the goal of this study it to test the hypothesis that a single prolonged stress exposure can trigger neuroinflammation priming in the BLA, and block the initial stress-induced neuroinflammation in the BLA using glycyrrhizin, an HMGB1 inhibitor, or LPS-RS, a competitive TLR4 antagonist, can effectively prevent subsequent impairment of fear extinction.

\section{Materials and Methods}

\section{Animals}

Male Sprague-Dawley rats $(n=144)$ that weighed $220-250 \mathrm{~g}$ at the time of surgery were obtained from the Shanghai Laboratory Animal Center, and were housed individually under $12 \mathrm{~h}$ light/dark cycle (lights on/off at $7 \mathrm{am} / 7 \mathrm{pm}$ ) and had free access to food and water. All animal experiments were approved by the Institutional Animal Care and Use Committee of Quanzhou 1st Hospital Affiliated to Fujian Medical University, China. The housing and treatment of the rats followed the guidelines of the "Guide for the Care and Use of Laboratory Rats" (Institute of Laboratory Animal Resources, Commission on Life Sciences 2011).

One week prior to the single prolonged stress (SPS) treatment, bilateral cannula aimed at the basolateral amygdala (BLA) was implanted using stereotaxic procedures. Animals were anesthetized with 


\section{Cellular Physiology Cell Physiol Biochem 2018;45:2529-2539 \begin{tabular}{l|l} 
and Biochemistry Published online: March 20, 2018 & $\begin{array}{l}\text { DOI: } 2018 \text { The Author(s). Published by S. Karger AG, Basel } \\
\text { www.karger.com/cpb }\end{array}$
\end{tabular}}

Lai et al.: Effects of SPS Treatment on Impaired Fear Memory Extinction

sodium pentobarbital ( $75 \mathrm{mg} / \mathrm{kg}$, i.p.), and local anesthetic ( $2 \%$ carbocaine, s.c.) was given at the incision site. The rat was placed into a Kopf stereotaxic instrument. The coordinates for BLA were A/P $-2.8 \mathrm{~mm}$, $\mathrm{M} / \mathrm{L}+5.0 \mathrm{~mm}, \mathrm{D} / \mathrm{V}-6.4 \mathrm{~mm}$ from skull, as determined from Bregma [24]. The end of the 26 gauge guide cannula (Plastics One, Roanoke, VA) was $2 \mathrm{~mm}$ above the BLA. Three skull screws $(0.80 \times 3 / 32$; Plastics One, Roanoke, VA) were used to anchor cannula with Ortho-Jet cold-setting dental acrylic (Lang Dental, Wheeling, IL). After surgery, rats returned to their home cage for 1 week until recovery.

\section{Single prolonged stress treatment and intracranial microinjection}

Prior to the procedure, rats were given microinjections. During the microinjections, animals were gently restrained in hand. The stylets were removed from the guide cannulae and $33 \mathrm{G}$ injection needles were inserted into the cannulae with $1 \mathrm{~mm}$ below the tip of the guide cannulae. The microinfusions of phosphate buffered saline (i.e., vehicle), Glycyrrhizin (HMGB1 inhibitor; $0.05 \mu \mathrm{g}, 0.2 \mu \mathrm{g}, 1 \mu \mathrm{g} / 0.5 \mu \mathrm{l} /$ hemisphere; Tocris Bioscience, Shanghai, China), or competitive TLR4 antagonist LPS-RS (1.5 $\mu$ g or $2.5 \mu \mathrm{g} / 0.5 \mu \mathrm{l} /$ hemisphere; InvivoGen, Shanghai, China). The dose of Glycyrrhizin and LPS-RS was chosen based on our pilot study and previous studies showing this range of doses. The injection needles were left in the guide cannulae for 1 min before and after the infusion. After the microinfusions were completed, the stylets were reinserted into the guide cannulae. The single prolonged stress (SPS) treatment was immediately started after microinjections. SPS treatment was modified based on literature [25, 26]. Briefly, rats were exposed to restraint for 2 hours, immediately followed by 20 minutes of forced swimming in a plastic tub $(60 \mathrm{~cm}$ in diameter and $50 \mathrm{~cm}$ in height) filled with warm water $\left(20-24^{\circ} \mathrm{C}\right)$. After being forced to swim for 20 minutes, rats were then exposed to ether $(75 \mathrm{ml})$ in a glass dessicator until they were fully anesthetized with no subsequent toe or tail pinch response. Thirty minutes later, rats were then placed in an electric shock box $(40 \times 30 \times 25 \mathrm{~cm})$ and 20 cycles of the foot shock ( $0.80 \mathrm{~mA}$ current, 11 s duration, 10 s interval) were administered. After electric shock, rats were returned to their home cages and were individually house until next experiment. Microinjections were also conducted once daily for 6 days.

\section{Contextual fear extinction}

During the contextual fear conditioning, rats were exposed to the novel context paired with a foot electric shock (0.8 mA, $4 \mathrm{~s}$ ) through a stainless steel grid floor (Med Associates Inc., USA). This novel environmental context was not previously associated with the foot shock during SPS treatment. After foot shock, rats were remained in the chamber for an additional $1 \mathrm{~min}$ before being returned to their home cages. During next four days, each rat was placed back in the conditioning chamber where it previously received foot shocked. The contextual fear response was interpreted by measuring the percentage of the duration of freezing behavior during 5 min exposure.

\section{Western blot}

Rats were euthanized by rapid decapitation and the brains were immediately dissected out, flash frozen in isopentane at $-20^{\circ} \mathrm{C}$, and stored at $-80^{\circ} \mathrm{C}$. The BLA tissue punches were taken using $19 \mathrm{Ga}$ neuropunches (Fine Science Tools). Punched tissue was stored at $-80^{\circ} \mathrm{C}$ in lysis buffer, containing $10 \mathrm{mM} \mathrm{HEPES}, 1 \%$ SDS, and $1 \mathrm{x}$ protease and phosphatase inhibitor cocktails (Sigma Aldrich, Shanghai, China). The total proteins were extracted, and Biorad DC Protein ${ }^{\mathrm{TM}}$ Assay kit was used to determine the protein concentrations. Proteins were then separated using sodium dodecyl sulfate-polyacrylamide gel electrophoresis (SDS-PAGE) at 120 $\mathrm{V}$ for $1 \mathrm{~h}$ and transferred onto nitrocellulose membranes for $1 \mathrm{~h}$ at $100 \mathrm{~V}$. Membranes were then incubated with primary antibodies against HMGB1 (1:1500, Abcam Cat\# ab79823 RRID:AB_1603373, Shanghai, China), RAGE (1:1500, Abcam Cat\# ab65965 RRID:AB_10864731, Shanghai, China), and TLR4 (1:1500, IMGENEX Cat\# IMG-428A RRID:AB_317485, Shanghai, China) overnight in 5\% skim milk solution at $4{ }^{\circ} \mathrm{C}$. After being rinsed 3 times in $0.05 \%$ Tween-Tris buffered solution (TTBS), membranes were then incubated in donkey anti-rabbit polyclonal secondary antibody (1:10, 000, GE Healthcare, Piscataway, NJ), conjugated to horseradish peroxidase (HRP) for $1 \mathrm{~h}$ followed by development with an enhanced chemiluminescence (ECL) system (Pierce Biotech, Rockford, IL, USA). $\beta$-actin (Santa Cruz, CA, USA; 1:1000) was used as loading control. Protein levels were quantified by densitometry using of NIH image J (NIH, Bethesda, MD, USA). HMGB1, RAGE, TLR4, and TNF $\alpha$ levels were normalized to the levels of the loading control, $\beta$-actin, and to baseline.

\section{KARGER}




\section{Cellular Physiology Cell Physiol Biochem 2018;45:2529-2539 \begin{tabular}{l|l} 
and Biochemistry Published online: March 20, 2018 & $\begin{array}{l}\text { (c) } 2018 \text { The Author(s). Published by S. Karger AG, Basel } \\
\text { www.karger.com/cpb }\end{array}$
\end{tabular}}

Lai et al.: Effects of SPS Treatment on Impaired Fear Memory Extinction

\section{Immunohistochemistry}

Immediately following the behavioral experiments, the rats were deeply anesthetized with sodium pentobarbital (100 mg/kg, i.p.) and perfused with cold $0.9 \% \mathrm{NaCl}$ followed by chilled $4 \%$ paraformaldehyde in $0.01 \mathrm{M}$ phosphate-buffered saline (PBS). The brains were post-fixed in the same fixative for $24 \mathrm{~h}$ at $4{ }^{\circ} \mathrm{C}$ and embedded in paraffin for sectioning at $4 \mu \mathrm{m}$. Coronal sections were made through the amygdala $(2-3 \mathrm{~mm}$ posterior to the bregma). Avidin-Biotin Complex (ABC) method was used to conduct immunohistochemical staining. To assess the microglial activation, ionized calcium-binding adaptor molecule 1 was labeled with antibody (Iba1; 1:500, Abcam Cat\# ab107159 RRID:AB_10972670, Shanghai, China). To assess astrocytic activation, glial fibrillary acidic protein (GFAP) was labeled with antibody (Abcam Cat\# ab7260 RRID:AB_305808, Shanghai, China). To assess the number of neurons, cells were labeled with anti-NeuN antibody (Abcam Cat\# ab104225 RRID:AB_10711153, Shanghai, China) was used. Sections were incubated with the primary antibodies for $16 \mathrm{~h}$ at $4{ }^{\circ} \mathrm{C}$. PBS was used as negative control. The sections were then incubated with the ABC solutions (ThermoFisher Scientific, Shanghai, China) at $37{ }^{\circ} \mathrm{C}$ for $20 \mathrm{~min}$, followed by counterstaining with Harris's hematoxylin.

\section{Cell counting}

Ten sections, which are centered at the microinjection site, are selected from the serial coronal sections of the amygdala of each brain. Olympus BX61 automatic microscope (Tokyo, Japan) was used to capture the images of amygdala section. The total numbers of cells that were stained with Iba1, GFAP, or neuronal nuclear antigen $(\mathrm{NeuN})$ in a $400 \times 400 \mu \mathrm{m}$ area (cannula tip centered) were marked by an experimenter who was blinded to the experimental conditions. Automated cell count was performed using an image analysis system. Cells that were morphologically intact and were clearly identifiable in the regions were included. Both hemispheres were counted, and the average number of cells of the right and left hemisphere for each section was calculated for each rat. The average number of cells in ten sections of each rat was calculated (ten sections/rat).

\section{Statistical Analysis}

Data were expressed as mean \pm SEM. We conducted power analysis to determine the sufficient sample size. Data were analyzed using one way or mixed-factorial analyses of variance (ANOVAs), where appropriate. Significant ANOVA main and interaction effects were further investigated using Tukey post hoc tests, when appropriate. Alpha was set at 0.05 .

\section{Results}

A single prolonged stress exposure triggered an increased HMGB1 levels in the BLA and impaired extinction of contextual fear memory

Six days after SPS treatment, rats received contextual fear conditioning

training followed by extinction testing for 4 consecutive days (Fig. 1A). SPS treatment prolonged the extinction of fear memory in rats (multi-factorial ANOVA, Tukey test, $\mathrm{p}<0.05$; Fig. 1B). Specifically, rats exhibited similar freezing behavior when re-exposed to fear context during the first day of extinction. However, during the next three days of extinction, rats that received SPS treatment exhibited enhanced freezing behavior

Fig. 1. Effects of SPS exposure on subsequent extinction of contextual fear memory. (A) Experimental design and time line. (B) Extinction of contextual fear memory ( $\mathrm{n}=8$ /group).
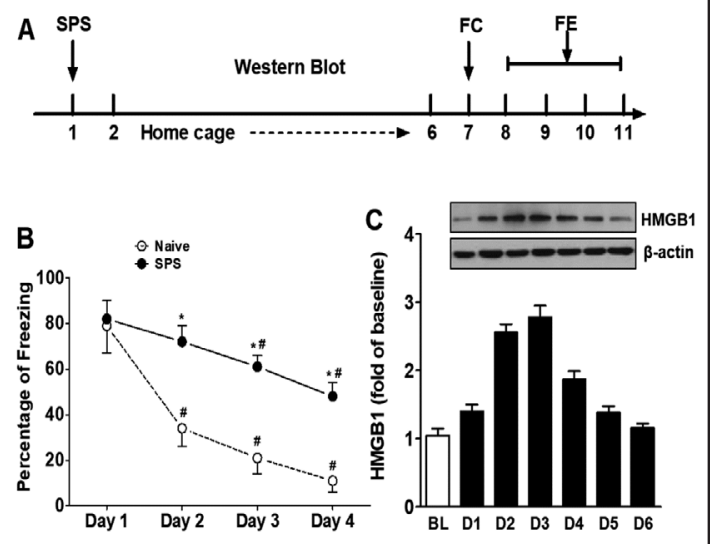

(C) Expres-

sion levels of HMGB-1 in the BLA before (Baseline, BL) and after (D1D6) SPS (n=8/time point). FC: Fear conditioning; FE: Fear extinction. 
as compared with naïve control group (Tukey test, $\mathrm{p}<0.05$; Fig. 1B). Importantly, this impaired fear extinction was associated with increased levels of HMGB1 in the BLA during the first 4 days after SPS treatment (one-way ANOVA, Tukey test, $\mathrm{p}<0.05$; Fig. 1C).

A single prolonged stress exposure triggered HMGB1/TLR4-mediated signaling in the BLA

Because HMGB1 is critical for regulating pro-inflammatory cytokine release [2729 ], we also examined the effects of SPS treatment on HMGB1-mediated downstream signaling. We found that rats received SPS treatment exhibited increased expression levels of TLR4 in the BLA (one-way ANOVA, Tukey test, $p<0.05$; Fig. $2 \mathrm{~A}, 2 \mathrm{~B}$, and $2 \mathrm{C}$ ). The levels of HMGB1 returned to similar levels seen in naïve control rats on day 6 before the subsequent fear conditioning (data not shown). However, the expression levels of RAGE in the BLA were not altered after SPS treatment. These results suggested that SPS treatment triggers cytokine release likely via activation HMGB1/TLR4-mediated signaling pathway.

Repeated bilateral intra-BLA infusions of Glycyrrhizin prevented the impairment of fear extinction

Because we found that HMGB1 levels were upregulated after SPS treatment, we then examined whether inhibition of HMGB1 signaling could have impact on subsequent fear extinction. Rats received bilateral intra-BLA injections of vehicle or glycyrrhizin preSPS treatment and post-SPS treatment once daily (Fig. 3A). Similarly, vehicle-treatment rats exhibited impaired fear extinction after SPS treatment, suggesting the microinjections procedure did not have influence on fear extinction. However, intra-BLA injections of glycyrrhizin dose-dependently reduced freezing behavior as compared with SPS group (Tukey test, $p<0.05$; Fig. 3B).

Repeated bilateral intra-BLA infusions of Glycyrrhizin reduced activation of microglia and astrocytes

The activation of microglia and astrocytes was examined in the amygdala of rats following the last behavioral testing. SPS treatment enhanced Iba1-immunoreactivity 
compared to naïve control group (data not shown). Enhanced Iba1immunoreactivity and small cell bodies with extensive ramifications in the amygdala was seen in naïve control group (Fig. 4A). However, SPS treatment produced a greater increase in Iba1-immunoreactivity (one-way ANOVA, Tukey test, $p<0.05$; Fig. 4A). Furthermore, repeated intra-BLA injections of glycyrrhizin dose-dependently decreased Iba1immunoreactivity in the BLA (Tukey test, $p<0.05$; Fig. 4A). These results suggested that glycyrrhizin treatment prevent the increase of microglia activation during fear extinction.

Similar to microglia activation, we also found thatSPS treatment enhanced GFAP-immunoreactivity compared to naïve control group (data not shown). SPS treatment produced a greater increase in GFAP-immunoreactivity (one-way ANOVA, Tukey test, $p<0.05$; Fig. 4B). Furthermore, repeated intra-BLA injections of glycyrrhizin dose-dependently decreased GFAPimmunoreactivity in the BLA (oneway ANOVA, Tukey test, $p<0.05$; Fig. 4B). These results suggested that glycyrrhizin treatment prevent the increase of astrocyte activation during fear extinction.

Additionally, we also evaluate whether the SPS and/or glycyrrhizin treatments induced neuronal loss in the amygdala. As shown in Fig. 4C, we did not find any difference in NeuN immunoreactivity among all the groups. Thus, these results indicate that SPS treatment and infusions of glycyrrhizin did not induce neuronal loss in the amygdala.

Finally, after analyzing all data showing in Fig. 4, we found that microglial and astrocytic activation levels were positively correlated with percentage of freezing in rats (Fig. 5A and B).

The SPS-induced fear extinction impairment was reversed by intra-BLA administrations of LPS-RS

Given that TLR4 is a critical receptor for HMGB1, and we found increased TLR4 expression in the BLA following SPS, we further investigated the possible neuropathological role of TLR4 in the BLA after SPS treatment in the development of fear extinction impairment (Fig. 6A). Replicating our results, we found that SPS treatment prolonged the extinction of fear memory in rats (multi-factorial ANOVA, Tukey test, $p<0.05$; Fig. 6B). Specifically, rats in all

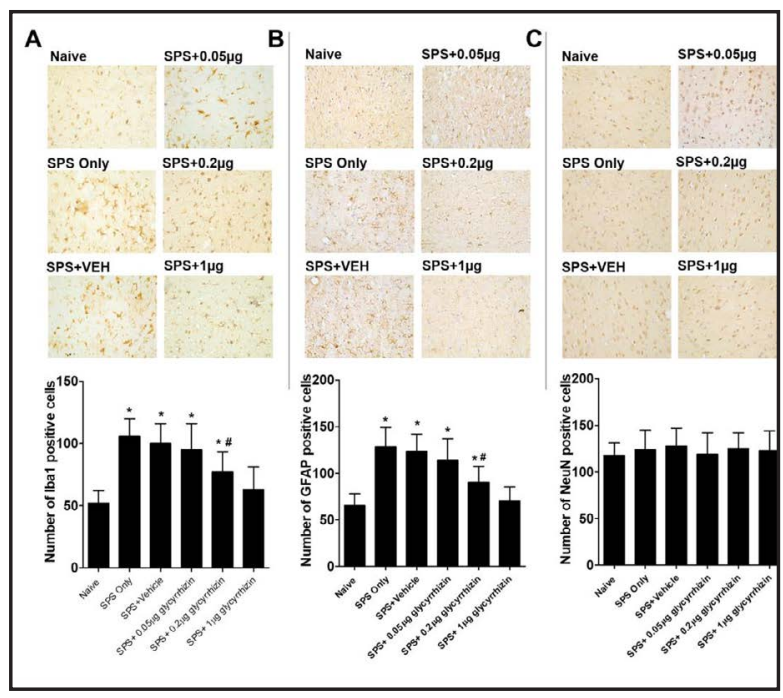

Fig. 4. Effects of intra-BLA administrations of glycyrrhizin on subsequent microglia and astrocyte activation in the BLA following contextual fear extinction ( $n=8 /$ group). (A) microglia in the BLA. (B) Immunohistochemical analysis of histochemical analysis of NeuN-immunopositive neuronal cells in the BLA. Asterisks represent the significant effects ment group, $\mathrm{p}<0.05$.

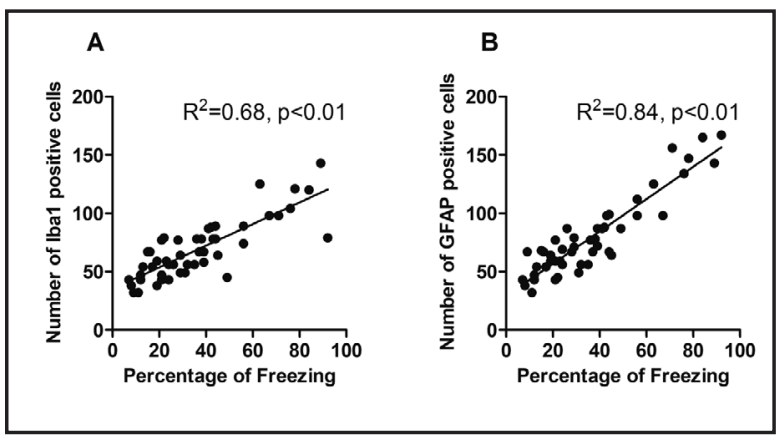

Fig. 5. Correlation of freezing behavior and (A) microglial and (B) astrocytic activation levels in the BLA. $\mathrm{R}^{2}$ : coefficient of determination. Immunohistochemical analysis of Iba1-immunopositive GFAP-immunopositive astrocyte in the BLA. (C) Immunoas compared with naïve control group, $\mathrm{p}<0.05$. Pond repsignificant effect as compared with SPS treat- 
groups exhibited similar freezing behavior when re-exposed to fear context during the first day of extinction. However, during the next 3 days of extinction, rats that received SPS and vehicle treatments exhibited increased freezing behavior as compared with naïve control group (Tukey test, $p<0.05$; Fig. 6B). Reversely, during the next 3 days of extinction, rats that received $2.5 \mu \mathrm{g}$ LPSRS exhibited reduced freezing behavior as compared with SPS and vehicle group (Tukey test, $p<0.05$; Fig. 6B). These results suggested that TLR4-mediated signaling plays a vital role in the development of fear extinction impairment after SPS treatment.

\section{Discussion}

The present study was the first to examine the role of HMGB1 in the development of PTSD-like behaviors. We found that SPS treatment prolonged the extinction of contextual fear memory after the SPS treatment, which was consistent with several previous studies $[8,9,25,26,30]$ The impairment of SPS-induced extinction of contextual fear memory was associated with increased HMGB1 and TLR4 levels in the BLA following SPS treatment. Additionally, the impairment of SPS-induced extinction of contextual fear memory was associated with increased activation of microglia and astrocyte in the BLA. Inhibition of HMGB1 in the BLA pre-SPS and post-SPS treatment can prevent the development of fear extinction impairment. Finally, we confirmed that TLR4 in the BLA is critical for the preventative effects of glycyrrhizin. Taken together, these results suggested that SPS treatment may not only produce short term effects on the HMGB1/TLR4-mediated pro-inflammation, but alter the response of microglia and astrocytes to the exposure to fear associated contextual stimuli.

Microglia are key effectors of neuroinflammatory processes. Unlike other CNS macrophages, microglia are maintained in the adult central nervous system (CNS) independent of circulating blood monocytes and are thought to self-renew from progenitor cells in the CNS [31]. Recent studies on microglia have revealed that a primed activation state may be induced in microglia under several neuroinflammatory conditions [32] after exposure to psychological stressors and stress hormones such as glucocorticoids [33]. Specifically, upon exposure to a pro-inflammatory stimulus, the pro-inflammatory cytokine response of microglia is potentiated beyond normal condition. For example, prior exposure to a severe acute stressor potentiates the pro-inflammatory response of microglia to a subsequent immune challenge (i.e. LPS) ex vivo [16]. When in this state, microglia will rapidly respond to inflammatory stimuli with exaggerated production of pro-inflammatory cytokines. Adding to this literature, the results in our study further suggested that HMGB1 is likely an important signal for priming microglia in the BLA after SPS, because when we infused HMGB1 inhibitor in the BLA, it significantly prevented microglia activation during fear extinction. This is consistent with a previous report that inescapable foot shocks increase HMGB-1 protein in the hippocampus, and blockade of HMGB-1 signaling using a competitive HMGB-1 antagonist, boxA, prior to foot shocks eliminated the exaggerated cytokine response of microglia exposed to LPS ex vivo $24 \mathrm{~h}$ after foot shocks [19].

Previous studies have also shown that HMGB1 can be quickly released into the cytoplasm following stress, injury, or disease [34], and can directly induce astrocyte activation [35]. Consistent to these findings, our results also showed that astrocytes activation was increased 


\section{Cellular Physiology Cell Physiol Biochem 2018;45:2529-2539

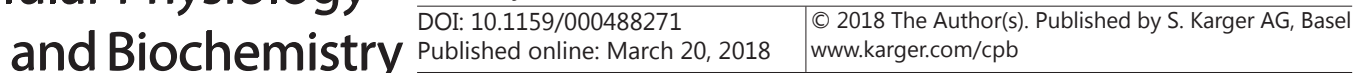

Lai et al.: Effects of SPS Treatment on Impaired Fear Memory Extinction

by previous SPS treatment. In our study, the enhanced reactive status of astrocytes in the BLA following SPS treatment could be due to the release of extracellular HMGB1, since HMGB1 inhibition reduced subsequent astrocyte activation in the BLA. As the major glial cell population in the CNS, astrocytes are critically involved in propagating and regulating neuroinflammation [36-39], although they are best known as support structures for neurons. Recent findings have revealed that astrocytes are capable of communication with neurons through the release of gliotransmitters such as glutamate, ATP, or cytokines [40]. In vitro studies have demonstrated that astrocytes can secrete cytokines in response to stimulation by inflammatory cytokines [41-43], which could disturb normal neuronal activities [44, 45]. Additionally, increased activation of astrocytes can alter the release and/or uptake of neurotransmitters [46], which affects the synaptic plasticity in fear extinction [47]. The results in our study suggested that this enhanced astrocyte activation could last a few days after SPS, and may increase the vulnerability of abnormal fear learning and/or extinction.

It has previously been shown that several cells of the CNS can actively export HMGB1 when exposed to appropriate stimuli [48-50]. Once released, HMGB1 can interact with various receptors, such as the receptor for advanced glycation end products (RAGE), TLR2 and TLR4, which are further transmembrane receptors, and can be engaged and activated by HMGB1 in brain cells $[51,52]$. However, there are three distinct forms of HMGB-1 characterized by post-transcriptional modification of the redox state of three critical cysteine residues (C23, C45, and C106). Fully reduced (fr) HMGB-1 is the predominant form that occurs under nonoxidizing conditions. fr-HMGB-1 has chemotactic properties produced by the formation of a hetero-complex with the chemokine CXCL12, which then signals through the chemokine receptor CXCR4 [53]. The pro-inflammatory form occurs under increased oxidizing conditions, in which a disulfide bridge forms between C23 and C45 (disulfide (ds) HMGB-1). This redox form interacts with TLR4 to induce synthesis and secretion of pro-inflammatory cytokines [54]. Finally, the fully oxidized form of HMGB-1 has no known biological activity [55]. While our study did not focus on examine which redox form of HMGB-1 is critical for SPS-induced fear extinction impairment, it is likely that dsHMGB-1 might be the vital one. It has been shown that central administration of dsHMGB-1, but not frHMGB-1, primed hippocampal microglia to LPS ex vivo [19]. Furthermore, dsHMGB-1 is a ligand for TLR4, while frHMGB-1 interacts with CXCR4 via CXCL12 [27]. Signaling at TLR4 initiates an intracellular signaling cascade that activates the immune-related transcription factor NF- $\kappa B$ [56] Therefore, the ability of dsHMGB-1 to prime microglia and astrocyte likely occurs via the TLR4/NF- $\kappa B$ pathway. This is supported by our results that intra-BLA microinjections of TLR4 inhibitor, LPS-RS, prevented the development of SPS-induced fear extinction impairment. Thus, our studies suggested that SPS via induction of increased secretion of dsHMGB-1 and activation TLR4-mediated signaling may prime the glia cells in the BLA leading to enhanced reactivity during fear learning and extinction. This primed state of glia cells in the BLA may induce abnormal neuro-glia interactions that are involved in the resistance of fear extinction.

Our study focused on male animals. However, women have greater risk than man to develop PTSD in the general population [57]. Hence, it is also important to examine the role HMGB1 in female animals. However, a lot of confounding factors, such as female gonadal hormone, may interfere with the effects of stressors on PTSD-like behaviors [58]. As a first step, we chose male animals, but future studies would be necessary to examine the sex difference in the role of HMGB1 in fear memory extinction after SPS treatment. Furthermore, the regulation of fear memory involves multiple critical brain regions and their interactions. For example, studies of Pavlovian fear conditioning and extinction in rodents and humans suggest that a neural circuit including the hippocampus, amygdala and medial prefrontal cortex is involved in the learning and memory processes that enable context-dependent behavior [59].

Future studies will be important to explore the role of HMGB-1 in fear memory in a circuitry level. This line of research will not only help understand the development of PTSD, but also provide an effective therapeutic target to treat fear memory abnormality associated with PTSD. 


\section{Cellular Physiology Cell Physiol Biochem 2018;45:2529-2539

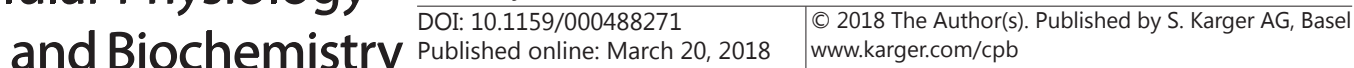

Lai et al.: Effects of SPS Treatment on Impaired Fear Memory Extinction

\section{Disclosure Statement}

The authors declare that they have no conflict of interest.

\section{References}

$>1$ Charney DS, Deutch AY, Krystal JH, Southwick SM, Davis M: Psychobiologic mechanisms of posttraumatic stress disorder. Arch Gen Psychiatry 1993;50:295-305.

-2 Howlett JR, Stein MB: Prevention of Trauma and Stressor-Related Disorders: A Review. Neuropsychopharmacol 2015;10.1038/npp.2015.261

-3 Ipser J, Seedat S, Stein DJ: Pharmacotherapy for post-traumatic stress disorder - a systematic review and meta-analysis. S Afr Med J 2006;96:1088-1096.

4 Hoskins M, Pearce J, Bethell A, Dankova L, Barbui C, Tol WA, van Ommeren M, de Jong J, Seedat S, Chen H, Bisson JI: Pharmacotherapy for post-traumatic stress disorder: systematic review and meta-analysis. $\mathrm{Br} \mathrm{J}$ Psychiatry 2015;206:93-100.

5 Brunello N, Davidson JR, Deahl M, Kessler RC, Mendlewicz J, Racagni G, Shalev AY, Zohar J: Posttraumatic stress disorder: diagnosis and epidemiology, comorbidity and social consequences, biology and treatment. Neuropsychobiology 2001;43:150-162.

6 Michopoulos V, Norrholm SD, Jovanovic T: Diagnostic Biomarkers for Posttraumatic Stress Disorder: Promising Horizons from Translational Neuroscience Research. Biol Psychiatry 2015;78:344-353.

7 Milad MR, Quirk GJ: Fear extinction as a model for translational neuroscience: ten years of progress. Ann Rev Psychol 2012;63:129-151.

-8 Yamamoto S, Morinobu S, Fuchikami M, Kurata A, Kozuru T, Yamawaki S: Effects of single prolonged stress and D-cycloserine on contextual fear extinction and hippocampal NMDA receptor expression in a rat model of PTSD. Neuropsychopharmacol 2008;33:2108.

$>9$ Knox D, George SA, Fitzpatrick CJ, Rabinak CA, Maren S, Liberzon I: Single prolonged stress disrupts retention of extinguished fear in rats. Learn Mem 2012;19:43-49.

10 Andrews JA, Neises KD: Cells, biomarkers, and post-traumatic stress disorder: evidence for peripheral involvement in a central disease. J Neurochem 2012;120:26-36.

11 Quinones MM, Maldonado L, Velazquez B, Porter JT: Candesartan ameliorates impaired fear extinction induced by innate immune activation. Brain Behav Immun 2016;52:169-177.

12 Gola H, Engler H, Sommershof A, Adenauer H, Kolassa S, Schedlowski M, Groettrup M, Elbert T, Kolassa I-T: Posttraumatic stress disorder is associated with an enhanced spontaneous production of pro-inflammatory cytokines by peripheral blood mononuclear cells. BMC Psychiat 2013;13:40.

13 de Pablos RM, Herrera AJ, Espinosa-Oliva AM, Sarmiento M, Muñoz MF, Machado A, Venero JL: Chronic stress enhances microglia activation and exacerbates death of nigral dopaminergic neurons under conditions of inflammation. J Neuroinflamm 2014;11:34.

14 de Pablos RM, Villaran RF, Arguelles S, Herrera AJ, Venero JL, Ayala A, Cano J, Machado A: Stress increases vulnerability to inflammation in the rat prefrontal cortex. J Neurosci 2006;26:5709-5719.

-15 Espinosa-Oliva A, De Pablos R, Villarán R, Argüelles S, Venero J, Machado A, Cano J: Stress is critical for LPSinduced activation of microglia and damage in the rat hippocampus. Neurobiol Aging 2011;32:85-102.

-16 Frank MG, Baratta MV, Sprunger DB, Watkins LR, Maier SF: Microglia serve as a neuroimmune substrate for stress-induced potentiation of CNS pro-inflammatory cytokine responses. Brain Behav Immun 2007;21:4759.

17 Wohleb ES, Fenn AM, Pacenta AM, Powell ND, Sheridan JF, Godbout JP: Peripheral innate immune challenge exaggerated microglia activation, increased the number of inflammatory CNS macrophages, and prolonged social withdrawal in socially defeated mice. Psychoneuroendocrino 2012;37:1491-1505.

18 Weber MD, Frank MG, Sobesky JL, Watkins LR, Maier SF: Blocking toll-like receptor 2 and 4 signaling during a stressor prevents stress-induced priming of neuroinflammatory responses to a subsequent immune challenge. Brain Behav Immun 2013;32:112-121.

19 Weber MD, Frank MG, Tracey KJ, Watkins LR, Maier SF: Stress induces the danger-associated molecular pattern HMGB-1 in the hippocampus of male Sprague Dawley rats: a priming stimulus of microglia and the NLRP3 inflammasome. J Neurosci 2015;35:316-324. 


\section{Cellular Physiology Cell Physiol Biochem 2018;45:2529-2539 \begin{tabular}{l|l} 
and Biochemistry $10.1159 / 000488271$ & $\begin{array}{l}\text { C) } 2018 \text { The Author(s). Published by S. Karger AG, Basel } \\
\text { www.karger.com/cpb }\end{array}$
\end{tabular}

20 Pape H-C, Pare D: Plastic synaptic networks of the amygdala for the acquisition, expression, and extinction of conditioned fear. Physiol Rev 2010;90:419-463.

-21 Kim JJ, Jung MW: Neural circuits and mechanisms involved in Pavlovian fear conditioning: a critical review. Neurosci Biobehav R 2006;30:188-202.

-22 Maren S, Quirk GJ: Neuronal signalling of fear memory. Nat Rev Neurosci 2004;5:844-852.

23 Sotres-Bayon F, Cain CK, LeDoux JE: Brain mechanisms of fear extinction: historical perspectives on the contribution of prefrontal cortex. Biol Psychiat 2006;60:329-336.

24 Paxinos G, Watson C: The rat brain atlas in stereotaxic coordinates, compact. Academic Press, New York. 1997.

-25 Knox D, Perrine SA, George SA, Galloway MP, Liberzon I: Single prolonged stress decreases glutamate, glutamine, and creatine concentrations in the rat medial prefrontal cortex. Neurosci Lett 2010;480:16-20.

-26 Yamamoto S, Morinobu S, Takei S, Fuchikami M, Matsuki A, Yamawaki S, Liberzon I: Single prolonged stress: toward an animal model of posttraumatic stress disorder. Depress Anxiety 2009;26:1110-1117.

27 Yang H, Antoine DJ, Andersson U, Tracey KJ: The many faces of HMGB1: molecular structure-functional activity in inflammation, apoptosis, and chemotaxis. J Leukocyte Biol 2013;93:865-873.

28 Yang H, Lundbäck P, Ottosson L, Erlandsson-Harris H, Venereau E, Bianchi ME, Al-Abed Y, Andersson U, Tracey KJ, Antoine DJ: Redox modification of cysteine residues regulates the cytokine activity of high mobility group box-1 (HMGB1). Mol Med 2012;18:250.

29 Yang H, Hreggvidsdottir HS, Palmblad K, Wang H, Ochani M, Li J, Lu B, Chavan S, Rosas-Ballina M, Al-Abed Y: A critical cysteine is required for HMGB1 binding to Toll-like receptor 4 and activation of macrophage cytokine release. P Natl Acad Sci USA 2010;107:11942-11947.

30 Wu ZM, Zheng CH, Zhu ZH, Wu FT, Ni GL, Liang Y: SiRNA-mediated serotonin transporter knockdown in the dorsal raphe nucleus rescues single prolonged stress-induced hippocampal autophagy in rats. J Neurol Sci 2016;360:133-140.

-31 Katsumoto A, Lu H, Miranda AS, Ransohoff RM: Ontogeny and functions of central nervous system macrophages. J Immunol 2014;193:2615-2621.

-32 Perry VH: The influence of systemic inflammation on inflammation in the brain: implications for chronic neurodegenerative disease. Brain Behav Immun 2004;18:407-413.

-33 Frank MG, Watkins LR, Maier SF: The permissive role of glucocorticoids in neuroinflammatory priming: mechanisms and insights. Curr Opin Endocrinol 2015;22:300.

34 Lotze MT, Tracey KJ: High-mobility group box 1 protein (HMGB1): nuclear weapon in the immune arsenal. Nature reviews. Immunology 2005;5:331.

35 Pedrazzi M, Patrone M, Passalacqua M, Ranzato E, Colamassaro D, Sparatore B, Pontremoli S, Melloni E: Selective proinflammatory activation of astrocytes by high-mobility group box 1 protein signaling. J Immunol 2007;179:8525-8532.

36 Farina C, Aloisi F, Meinl E: Astrocytes are active players in cerebral innate immunity. Trends Immunol 2007;28:138-145.

-37 Liu S, Kielian T: MyD88 is pivotal for immune recognition of Citrobacter koseri and astrocyte activation during CNS infection. J Neuroinflamm 2011;8:35.

38 Norden DM, Fenn AM, Dugan A, Godbout JP: TGF $\beta$ produced by IL - 10 redirected astrocytes attenuates microglial activation. Glia 2014;62:881-895.

39 Norden DM, Trojanowski PJ, Villanueva E, Navarro E, Godbout JP: Sequential activation of microglia and astrocyte cytokine expression precedes increased iba - 1 or GFAP immunoreactivity following systemic immune challenge. Glia 2016;64:300-316.

40 Ricci G, Volpi L, Pasquali L, Petrozzi L, Siciliano G: Astrocyte-neuron interactions in neurological disorders. J Biol Phy 2009;35:317-336.

41 Cartier L, Hartley O, Dubois-Dauphin M, Krause KH: Chemokine receptors in the central nervous system: role in brain inflammation and neurodegenerative diseases. Brain Res Brain Res Rev 2005;48:16-42.

-42 van Kralingen C, Kho DT, Costa J, Angel CE, Graham ES: Exposure to inflammatory cytokines IL-1 $\beta$ and $\mathrm{TNF} \alpha$ induces compromise and death of astrocytes; implications for chronic neuroinflammation. PloS one 2013;8:e84269.

43 Meeuwsen S, Persoon - Deen C, Bsibsi M, Ravid R, Noort JMV: Cytokine, chemokine and growth factor gene profiling of cultured human astrocytes after exposure to proinflammatory stimuli. Glia 2003;43:243-253. 


\section{Cellular Physiology Cell Physiol Biochem 2018;45:2529-2539 \begin{tabular}{l|l} 
and Biochemistry Published online: March 20, 2018 & $\begin{array}{l}\text { () 2018 The Author(s). Published by S. Karger AG, Basel } \\
\text { www.karger.com/cpb }\end{array}$ \\
\hline
\end{tabular}}

Lai et al.: Effects of SPS Treatment on Impaired Fear Memory Extinction

44 Hoyo-Becerra C, Schlaak JF, Hermann DM: Insights from interferon- $\alpha$-related depression for the pathogenesis of depression associated with inflammation. Brain Behav Immun 2014;42:222-231.

45 Lynch MA: Neuroinflammatory changes negatively impact on LTP: A focus on IL-1 $\beta$. Brain Res 2015;1621:197-204.

46 Halassa MM, Haydon PG: Integrated brain circuits: astrocytic networks modulate neuronal activity and behavior. Ann Rev Physiol 2010;72:335-355.

-47 Jo S, Yarishkin O, Hwang YJ, Chun YE, Park M, Woo DH, Bae JY, Kim T, Lee J, Chun H: GABA from reactive astrocytes impairs memory in mouse models of Alzheimer's disease. Nat Med 2014;20:886-896.

-48 Kim J-B, Choi JS, Yu Y-M, Nam K, Piao C-S, Kim S-W, Lee M-H, Han P-L, Park J-s, Lee J-K: HMGB1, a novel cytokine-like mediator linking acute neuronal death and delayed neuroinflammation in the postischemic brain. J Neurosci 2006;26:6413-6421.

49 Passalacqua M, Patrone M, Picotti G, Del Rio M, Sparatore B, Melloni E, Pontremoli S: Stimulated astrocytes release high-mobility group 1 protein, an inducer of LAN-5 neuroblastoma cell differentiation. Neuroscience 1997;82:1021-1028.

50 Wang H, Vishnubhakat JM, Bloom O, Zhang M, Ombrellino M, Sama A, Tracey KJ: Proinflammatory cytokines (tumor necrosis factor and interleukin 1) stimulate release of high mobility group protein-1 by pituicytes. Surgery 1999;126:389-392.

51 Hori O, Brett J, Slattery T, Cao R, Zhang J, Chen JX, Nagashima M, Lundh ER, Vijay S, Nitecki D: The receptor for advanced glycation end products (RAGE) is a cellular binding site for amphoterin mediation of neurite outgrowth and co-expression of rage and amphoterin in the developing nervous system. J Biol Chem 1995;270:25752-25761.

52 Park JS, Svetkauskaite D, He Q Kim J-Y, Strassheim D, Ishizaka A, Abraham E: Involvement of toll-like receptors 2 and 4 in cellular activation by high mobility group box 1 protein. J Biol Chem 2004;279:73707377.

53 Schiraldi M, Raucci A, Muñoz LM, Livoti E, Celona B, Venereau E, Apuzzo T, De Marchis F, Pedotti M, Bachi A: HMGB1 promotes recruitment of inflammatory cells to damaged tissues by forming a complex with CXCL12 and signaling via CXCR4 J Exp Med 2012;209:551-563.

54 Antoine DJ, Harris HE, Andersson U, Tracey KJ, Bianchi ME: A systematic nomenclature for the redox states of high mobility group box (HMGB) proteins. Mol Med 2014;20:135-137.

55 Venereau E, Casalgrandi M, Schiraldi M, Antoine DJ, Cattaneo A, De Marchis F, Liu J, Antonelli A, Preti A, Raeli L, Shams SS, Yang H, Varani L, Andersson U, Tracey KJ, Bachi A, Uguccioni M, Bianchi ME: Mutually exclusive redox forms of HMGB1 promote cell recruitment or proinflammatory cytokine release. J Exp Med 2012;209:1519-1528.

56 Kawai T, Akira S: Signaling to NF-kappaB by Toll-like receptors. Trends Mol Med 2007;13:460-469.

57 Breslau N: Gender differences in trauma and posttraumatic stress disorder. JGSM 2002;5:34-40.

58 Glover EM, Jovanovic T, Mercer KB, Kerley K, Bradley B, Ressler KJ, Norrholm SD: Estrogen levels are associated with extinction deficits in women with posttraumatic stress disorder. Biol Psychiat 2012;72:1924.

59 Maren S, Phan KL, Liberzon I: The contextual brain: implications for fear conditioning, extinction and psychopathology. Nat Rev Neurosci 2013;14:417-428. 